\title{
A Study on Technological Management Strategy in SMEs
}

\author{
Seong-Ho, Yi \\ Doctor course in Management of Technology, Graduate school, Sungkyunkwan University, South Korea \\ E-mail: seongho0906@gmail.com
}

Received: September 15, 2012

doi:10.5430/jms.v3n4p24

\author{
Accepted: October 15, 2012 \\ Online Published: October 31, 2012 \\ URL: http://dx.doi.org/10.5430/jms.v3n4p24
}

\begin{abstract}
The technology is taken into consideration as a resource of the business, in addition to the four traditional resources: material resources, financial resources, human resources and informational resources. This makes important for the managers to have solid technological knowledge, in addition to the economics. The research regarding the technological management (or the management of technology - MOT) is essential for human being from past, present to future.. Technology transfer is recognized as a critical issue to strengthen industry competitiveness in today's global and knowledge-based economies. The vertical transfer of technology from R\&D labs to industries is becoming more emphasized than the horizontal company-to-company transfer of commercialized technology. The network and cooperation among technology transfer intermediates are becoming more important with the increasing demand of the comprehensive technology transfer services.
\end{abstract}

Keywords: Technological management, Resources of a business, Technological system, Technology, Technology transfer

\section{Introduction}

Recent experiences of newly industrialized countries have given us the lesson that maintenance of a high rate of economic growth itself is not a panacea. Korea is not an exception. Despite the marvelous recent records of economic growth, Korea is suffering from various structural problem such as unemployment and underemployment, unequal income distribution, a growing dependence on foreign countries, and so on. Present Korean economic conditions call for a new strategy of economic development.

As is well known, the lack of natural resources along with the small size of domestic markets forced Korea to adopt an outward-looking development strategy from the 1960's and development of science and technology has been more and more emphasized during the 1980 's to maintain and strengthen its external competitiveness. Although inflation has been well under control and high economic growth has been maintained in recent years, there still remains the problem of unemployment and underemployment. In addition to technological development, efficient development and utilization of relatively abundant human resources will be the crucial factor which determines the future of the Korean economy. In this context, it has frequently pointed out that the most effective strategy is to reorganize the industrial structure in the direction of developing capital-saving, skill-intensive and technology-intensive industries. In fact, the government has been pursuing economic policies toward this direction. There is, however, an increasing concern about the conflict between employment and economic growth, especially in connection with factory and office automation. From the viewpoint of the growth strategies of specific firms or industries, the conflict seems to be inevitable. As was mentioned above, the growth of Korean firms or industries depends more on foreign demands rather than on domestic demands. In order to survive in international competition, Korean firms are sometimes forced to import advanced capital-intensive technologies. Korean entrepreneurs seem to believe that the labor-and skill-intensive technologies which can develop and utilize the relatively abundant human resources are not compatible with their firms' growth strategies. In the simple Keynesian macroeconomic model, (Note 1) output growth directly raises employment level. Does the model make sense only at the macro level and is it not relevant to specific firms and industries which actively react to technological changes? Is the trade-off between output growth and rise in employment irremediable? Before tackling this problem, let us cite an example from another country. Research on milling factories in India reported that the output-capital ratio of more labor-intensive milling technology actually turned out to be smaller than that of a less labor-intensive one, and that the more labor-intensive the technology was, the more capital was employed. (Note 2) Other research on two cotton weaving factories in India found out that labor-intensive technology is also capital-saving technology. The above research evidently 
denies the existence of a trade-off between output growth and employment expansion. (Note 3)

Despite several limitations in the methodologies of the above studies, (Note 4) the studies provide us with a keen insight into the problem since they are empirical studies on specific firms in a labor-abundant developing country. The purpose of this paper is to examine the problems of current management and labor policies toward technological development and to discuss the advisable management and labor strategies to take advantage of relatively abundant human resources and to minimize labor-management disputes over the issue of technological development.

\section{Problems of Technology Development in Korea}

One of the best strategies for technological development might be to develop necessary technologies by themselves, but most Korean firms which lacked qualified R \& D manpower and funds had no alternative but to import them from advanced foreign countries. In this section, let us examine some of the problems in connection with the technological development policies of the Korean firms.

\subsection{Overlapping in Technologies Imported}

Korean firms have a tendency to import technologies parts of which are already domestically available or which can be developed easily by improving existing technologies. This results from excessive competition among domestic firms and from the lack of adequate self-evaluation of the various kinds of know-how which they presently hold. This kind of overlapping is also due to the low participation of production managers in the decision-making process of the importation of technology. The production managers should be the best qualified personnel to properly evaluate the contents of the technologies to be imported. From the next table we can see that the participation of the technological managers in the process of suggestion and decision-making as to technology import takes the lion's share and that the participation of the production managers takes a small part.

\subsection{Inappropriate Technology}

Appropriate technology can be defined as the one which can most efficiently utilize production factors in the long run in the light of the relative factor endowments. Let us briefly examine a relevant index indicating the extent to which imported technologies have been absorbed and applied to the actual process of production. The last two columns of Table 2 show the percentage of the number of firms which can be regarded as importing technologies which have been perfectly or properly absorbed and applied. From Table 2 we can see that $76.1 \%$ of the firms surveyed have imported appropriate technologies. At the same time it also indicates the remaining $23.7 \%$ of the firms have imported inappropriate technologies. Along with the fact that more than $80 \%$ of the imported technologies are outdated ones or past maturity stages in their life cycles, this partial failure of the technology import suggests that there has been an unnecessary burden on production costs. It may be conjectured that increases in production costs have a negative effect on employment.

\subsection{Low Level of High Technology Introduction}

Table 3 shows the levels of imported technology from foreign countries by the size of importing firms. According to the table, more than $80 \%$ of the Korean firms surveyed imported transitional or specific patterns of technologies rather than fluid ones which could be regarded as high technology. Therefore, this fact indicates that the Korean firms' are not willing to develop high technology which can create new market demand, but, rather, are satisfied to import the technology which can decrease unit cost and improve the quality of existing products. In some cases, they are just importing foreign trademarks. Actually it is well known that food and textile industries have imported the well-known trademarks of foreign firms. (Note 5)

\subsection{Excessive Dependence on Japan and the U.S.A.}

When we analyze major differences against each industry in technology export, we can figure out export decrease on electricity \& electronics and construction area. However, other areas' export volumes are increased a lot. Regarding to Technology Import(introduction), total import volume is increased shown as table 5. When we examine the origin of countries from which technologies were imported among trade deficit countries in 2010, USA occupies the largest percentage, $57.4 \%$, as is shown in Table 5 . Next is $12.3 \%$ from the Japan. Together Japan and the U.S.A. enjoy the predominant share of $69.7 \%$.

Not to speak of the probability that excess dependence on the two countries increases importing costs because of weak bargaining power, there is a serious doubt whether the imported technologies are appropriate from the viewpoint of the Korean factor endowment because the technologies developed by U.S.A. and Japan are known to be capital-intensive. 


\subsection{Inactive Role of Medium and Small Firms}

The large scale firms have played a key role in technology import. As is shown in Table 6,81 cases out of 126 were contracted by large companies. The method of import was mostly selected by importing companies.

The technology importation which has been predominantly conducted by large firms has reduced bargaining power and increased import costs through excessive competition among the large firms. We can also think of the cost caused by complex and procrastinated decision-making processes within the large firms. Although, considering relative advantages in information, etc., large firms are expected to have much stronger bargaining power than small and medium firms, empirical studies show that the strength of the bargaining power between them is not very different.

\subsection{Low and Inefficient Domestic $R \& D$ Activities}

Let us briefly examine the in-house development of technology. As is well known, the Korean government has implemented various policies for the development of science and technology, (Note 6) Nonetheless, investment expenditure on R \& D has not been sufficient in comparision with other countries. For example, it occupies only $1.06 \%$ of GNP as of 1985. (Note 7) Excluding the government expenditures on R \& D, the share of R \& D expenditures in total production cost in Korean enterprises is much smaller, Although there has been no comprehensive empirical analysis of the present status of in-house development of technology, we can point out the following two problems. First, after deciding a certain percentage of total sales revenue as an investment fund for $\mathrm{R}$ $\& \mathrm{D}$, Korean firms have a tendency to allocate the fund equally to all technological sectors. It is quite doubtful whether this kind of fund allocation is conducive to the development of appropriate technology, taking advantage of the mobilization of abundant human resources.

Second, Korean firms have not yet sufficiently utilized domestically available technology information which would have economized on the $\mathrm{R} \& \mathrm{D}$ costs because $\mathrm{R} \& \mathrm{D}$ has been conducted within the boundary of individual companies; as is shown in Table 7, 82.3\% of the firms surveyed are doing R \& D independently. This tendency is more obvious in the case of large firms, excluding the joint R \& D with other domestic firms, their reluctance to work jointly with domestic research institutes may aggravate technological unemployment problems by the possibility of developing inappropriate technology.

\section{Resource Cost of Technology Transfer}

The various participants in international technology transfer prefer to view the costs from their own perspectives. The licensee country may view the foreign exchange costs and costs in terms of externalities as the essence of technology transfer costs. Foreign exchange costs are perhaps the most obvious cost item especially to less industrialized countries, both because foreign exchange is particularly scarce in many of those countries and because the import of technology frequently involves substantial foreign exchange outlay over a period of time. Costs in terms of externalities are those costs which do not accrue directly to any specified project of technology import but indirectly to the rest of the economy. (Note 8) For example, the introduction of foreign technology may discourage local R \& D activities. The licensor country, on the other hand, may consider the erosion of its technological lead in strategic industries as the key element of technology transfer costs. The technology buyer may view direct charges such as royalties, technical assistance fees, etc., indirect charges through tying various non-technological inputs, and restrictive clauses as technology transfer costs. The licensor on the other hand is likely to consider the erosion of its technological lead, loss of export sales, time of managerial and technical personnel spent in transfer activities, and additional $\mathrm{R} \& \mathrm{D}$ expenses in adapting technology to local conditions as being the key element in any calculation of transfer costs. Although the various participants view the costs of technology transfer differently, only one set of activities is involved in a given technology transfer. In this sense, there is only one true technology transfer cost. This can be called the resource cost of technology transfer.

Since we want to develop the concept of distributable returns from a given technology transfer, we will employ the above definition of resource cost of technology transfer. All the relevant costs should be included to the extent that they are necessary for the effective transfer of a given technology, irrespective of which entity initially or eventually incurs them. The definition of the resource cost presented at the conceptual level can be translated into operational measures of transfer costs by considering the nature of activity and the costs involved. Indentification of the nature of activity and the costs involved in a given technology transfer can be possible through use of a technology transfer matrix as suggested by Behrman and Wallender. (Note 9) According to them, technology transfer occurs over seven distinct phases: Proposal \& planning, product design, plant design and construction, start-up, value engineering and controls, product development, and external support. For each type of technology, different mechanism will be found 
appropriate. There are five general mechanisms of transfer:(1) documentation in the form of manuals, specifications, layouts, designs, and so forth; (2) instruction programs that is, formal education and on-the-job training; (3) visits and exchanges of technical personnel; (4) development and transfer of specialized equipment;(5) and continuing oral and written communication on whatever problems may arise. On a well-defined product technology, the relationship of different phases of technology to be purchased and the mechanisms available to transfer them can be conceptualized in a matrix form. The matrix can be of considerable value to licensee (as well as licensor) seeking to determine what kinds of technology is wanted and what the problems are of precluding transfers of specific types of technology. Accordingly, for effective transfer of a given technology, certain combinations of various phases of the technology with specific mechanisms of transfer can be selected. Then, the resource cost can be regarded as the costs involved in realizing the particular way of transferring the technology.

\section{Management Strategy toward Technological Changes}

In the process of technological changes, there must be an equitable sharing of the fruits of innovation and increased productivity with the workers implementing the innovation along with good communication and cooperation between labor and management. When workers are thereby displaced, it is necessary for management to provide adequate compensation for those displaced workers and programs to assist their adjustment and reemployment. In a more positive way, the management should try to introduce appropriate technology which minimizes technologicaI unemployment. A strategy that is beneficial to both labor and management is urgently needed because of the external conflicts arising from volatile and harsh international competition and the internal conflicts involved with surplus population, unnecessary downfall of labor productivity and latent labor-management conflict. As was discussed above, more than $80 \%$ of the imported technologies can be classified as outdated or past the maturity stage in their life cycles so that their contribution to the development of domestic technology is limited.

Korean firms should try to import fluid patterns of technology to evade this problem. They should import more basic technology which can be applied in various processes of production rather than a specific pattern of technology. In other words, they should try to import technology which can lead process innovation and ideally speaking, product innovation must be developed domestically.

Korean firms should also try not to import the same content of technology competitively by several firms; it is reckless to import what is already available domestically or easily improvable with a little effort. In addition to the establishment of an adequate system of self-evaluation in each firm along with making arrangements for more participation by technology managers in the decision-making of technology imports and self-development, some measures are needed to evade unnecessary competition among firms to import the same technology. Various employers' associations such as the Korea Employers' Federation, the Federation of Korean Industries, the Korean Federation of Small Business, and the employers' association in each industry can play an important role in this respect.

It was mentioned that Korea depends too much on Japan and the U.S.A. in technology trade. This high degree of technology dependency reduces bargaining power and blocks the penetration of Korean products into other areas. Korean firms must diversify their technology sources. Japan is the number one source of technology imports, but she is the second after the U.S. in terms of royalties paid. This is due to the lack of core technology imported from Japan. Among the 686 technologies imported from Japan from 1981 to1984, according to a MOST survey, $47.5 \%$ are patent-related core technology. The percentage is relatively low compared to the U.S.' $58.7 \%$ or the $50 \%$ of European countries. (Note 10) Protectionism in technology transfers may be a prevailing phenomenon in the world today. Japan seems to be the case in point, because the Japanese are reluctant to transfer core technology since they are afraid of what they call a boomerang effect. Koreans should reduce their excessive dependency on Japan and seek more technology cooperation from such EU countries as West Germany, England, France, and Belgium, The introduction or the development of technologies should be performed more by medium and small enterprises or by each cell company of a conglomerate. (Note 11) It should be clearly understood that the bargaining power of medium and small enterprises is not much weaker than that of large enterprises in the process of bargaining with foreign firms. Medium and small entrepreneurship have advantages in their quick decision-making, strong entrepreneurship, easy adaptation and application of new technologies.

In cases where medium and small enterprises introduce new technologies while large firms readpot these fully adjusted technologies from them, possible errors could be prevented, and thereby the introduction costs of technology would be drastically reduced. Furthermore, the factor prices relevant to medium and small enterprises are less distorted since most of them have to pay the market rate of interest when they borrow capital. So, in a system where the introduction of technologies is performed by medium and small enterprises while large enterprises readopt 
them, labor-intensive technologies suitable to the Korean situation might be chosen.

In the preceding discussion, it was suggested that the labor-intensive industries of Korea still have comparative advantages. So it wouId be reckless to prematurely consider them as declining industries. More efforts should be made to find possible ways of maintaining and strengthening the comparative advantages. (Note 12) In the case of the textile industry, for example, Korea has already acquired a notable share and good reputation in the international market. If some investment is made in the development of original designs and product differentiation, and if multi-item-small-quantity system and flexible supply tactics suitable to shortened product life cycles are devised, the Korean textile industry can prolong and increase its share and raise its reputation in the international market. Considering the tendency of international trade, this kind of strategy is expected to contribute to the creation of new employment as well as the maintenance of existing employment. The indiscreet introduction of technology that causes the reversal of factor-intensities should be avoided. First of all, the choice of optimal technology should be discussed in the context of the increase in X-efficiency. The ILO dispatched a research committee to the enterprises of India, Burma, Indonesia, Malaysia, Taiwan, Pakistan and Israel to examine their productivity. It was reported that, without any net investment, these enterprises could save $25 \%$ of their costs merely by rearranging their production process, improving material management, and introducing incentive wage schemes. The most clear evidence of the result is the situation in Pakistan. (Note 13) Also, in the case of Korea, it is well known that many successful cases of Factory Saemaul Movements were reported.

It may be needless to emphasize that each enterprise should attempt to make complete use of the existing technology and production factors. This will result in capital-deepening or capital-intensification, which can lead to the adoption of capital-saving and labor-using technology. In its early stage of economic development, Japanese enterprises tried to fully utilize seemingly obsolete machinery, which absolutely contributed to the growth, stability and cost reduction. (Note 14) On the contrary, in the case of Kenya, they planned to develop the technology of roofing their houses with iron plates not with abundant and high-quality domestic bamboo. In consequence, Kenya had to import iron plates constantly. It was, of course, against the growth of firms and the welfare of workers. To be more specific, enterprises should adjust the existing technologies and modify the combination of the items of output to make more active use of their domestic raw materials, resources and technologies that have been wasted so far. Research on 21 less developed countries revealed that $91 \%$ of their GNP growth was due to the increase in the input of labor and capital and that only $9 \%$ was explained by the technologies imported from developed countries. (Note 15) This implies that the excessive import of technologies is not helpful to developing countries and that the maximum utilization of their domestic resources and existing technologies is the most urgent task they have. If this is done, technological unemployment would be lessened and managers could avoid excessive introduction and adoption of new technologies and hence could save a notable amount of costs. This saved money, in turn, can be invested in on-the-job-training and retraining of workers and, especially, training of technical manpower which is necessary for in-house development of technology. This way of technological adaptation would bring about higher growth of firms and create more employment, for it removes the frictional cost of adapting the skilled workers to newly imported technologies or of searching for the skilled workers suitable to those technologies, Research on the choice of appropriate technology should be performed more actively. The existing research of most Korean firms is largely confined to the digestion of imported technologies. Because of the severe reluctance of firms to reveal data on their technologies, the appropriateness of the adopted technology can never be easily explored. What is worse, even if this data is available, there is still a difficulty of measurement. Though, to my knowledge, there is no empirical study on the Korean case in this respect, it can be conjectured that Korea also has made mistakes similar to those of Ethiopia and Ghana. Ethiopia and Ghana adopted precipitously the most advanced capital-using technologies of developed countries in constructing their sugar and shoe factories, respectively. It is evident that these factories were inefficient from the viewpoint of both industrial firms and the economy as a whole. What should have been adopted was labor-using technologies suitable to the situations of those countries, Similar mistakes were also found in several industries in Indonesia. (Note 16) It is desirable for each firm to establish, if possible, its own R \& D institution that analyzes appropriate technology for that specific firm and suggest show to adapt to existing and new technologies. (Note 17) For this institution to be effective, it must be arranged for skilled workers who are actually involved in the production process to participate. A successful institution would enable the firm to determine which pattern of technology is required to purchase and to judge on which part R \& D investment has to be concentrated. There must be many firms in which establishing an independent R \& D institution is impossible or much too costly. In this case, joining an R \& D institution is desirable, Collaboration among firms in research on technology in any form is highly recommendable because of the following merits; i) chain-effects due to the reduction of R \& D costs, ii) reduction of information costs by the removal of excessive competition, iii) economies of scale that make possible R \& $\mathrm{D}$ 
investments easy and cheap, iv) saving of introduction costs of technology by means of enhanced bargaining power, v) utilization of information banks or libraries that prevent the overlapped introduction of technologies, vi) risk diversification and error minimization that enable firms to reduce personnel management costs, to prevent the waste of manpower and to establish stable long-term planning. (Note 18) Another alternative for an individual firm is to make full use of existing domestic research institutes. They also endeavor towards expanding exchange programs with advanced and developing countries, exemplified by joint international research and the mutual exchange of researchers, Industrial firms must therefore utilize these existing research institutes.

\section{Conclusion}

In order to meet the internal and external challenges in the process of rapid technological changes, management should try to introduce appropriate technology which can efficiently utilize the relatively abundant human resources and minimize the technological unemployment. In cases where unemployment is inevitable, management must bear some of the responsibility for adequate compensation, retraining, and relocation assistance for those displaced workers. It must be, of course, understood that it is not entirely a company responsibility to take care of those displaced. Part of the responsibility must be shared by the society through the government. It may be needless to say that management also has the obligation to share the fruits of technological innovation with labor. Some of the trade unions' strategies in the direction of encouragement of innovation were discussed. It was pointed out that the quality of the relationship between labor and management is critically important, In other words, cooperation between labor and management is necessary. It is, however, never too much to emphasize that genuine labor-management cooperation, through either collective bargaining or labor-management councils, is hard to realize without more or less equal power between them. Although unions must try to do their best to be stronger by themselves, much of the responsibility for maintaining reasonable balance of power between labor and management belongs to the government.

\section{References}

Adner, R., \& Levinthal, D. A. (2002). The emergence of emerging technologies. California Management Review, 45(1), 50-66.

Bulgerman, R., Maidique, M., \& Wheelwright, S. (2001). Strategic Management of Technology and Innovation (3rd ed.). Mc Graw-Hill, Boston.

Chanaron, J. J., Dominique, J., \& Soderquist, K. (2002). Technological management: a tentative research agenda. International Journal of Technology Management, 23(6), 618-629.

Davenport, S., Campbell-Hunt, C., \& Solomon, J. (2003). The dynamics of technology strategy: an exploratory study. R\&D Management, 33(5), 481-499.

Del Palacio, A. I., Solé, P. F., \& Montiel, C.H. (2006). University Spin-offs programmes: how can they support the NTBF creation?. International Entrepreneurship and Management Journal, 2(2), 157-172.

Fisher, E., \& Reuber, A.R. (2003). Public support for rapid growth firms: a comparison of the views of founders, government policy makers and private sector resource providers. Journal of Small Business Management, 41(4), 346-365.

Gibbons, P.T., \& O'Connor, T. (2003). Strategic posture, technology strategy and performance among small firms. Journal of Enterprising Culture, 11(2), 131-146.

Gregory, M. J. (1995). Technology Management: a process approach. Proceedings of the Institution of Mechanical Engineers, 209.

Narayan, V. (2001). Managing technology and innovation for competitive advantage. Prentice Hall, New Jersey.

Patton, M.Q. (2001). Quality research and evaluation methods (3rd ed.). Sage, Thousand Oaks.

Szántó, B. (2001). The paradigm of globalism. Technovation, 21(10), 673-687.

Tan, J., Fisher, E., Mitchell, R., \& Phan, P. (2009). At the center of the action: Innovation and technology strategy research in the small business setting. Journal of Small Business Management, 47(3), 233-262.

Tavares, R., \& Avila-Merino, A. (2008). Technology management. Training Manual, ICS UNIDO, Trieste.

Westphal, L.E. (2002). Technology strategies for economic development in a fast changing global economy. Economics of Innovation and New Technology, 11(4-5), 275-320.

White, M.A., \& Bruton, G.D. (2007). The management of technology and innovation. Canada: Thomson. 
Yin, R.K. (2002). Case Study Research - Design and Methods (3rd ed.). Sage, Thousand Oaks.

Zahra, S., \& Bogner, W. (2000). Technology strategy and software new ventures' performance: exploring the moderating effect of the competitive environment. Journal of Business Venturing, 15(2), 135-173.

\section{Notes}

Note 1. See J. E. Meade, An Introduction of Economic Analysis and Policy, Oxford University Press, London, 1983, p. 75-78, and A. P. Lerner, Economics of Employment, McGraw"Hill, New York, 1951. p. 193-195.

Note 2. A.S. Bhalla, "Choosing Techniques; Handpounding vs. Machine Milling of Rice; An Indian Case," Oxford Economic Papers, March 1965, p. I47-157.

Note 3. A.K. Sen, Choice of Techniques (3rd edition), Augustus M. Kelley, New York, 1968,

Note 4. Chang Young Jung, Conflicts between Output and Employment, The Korea Economic Research Center, Seoul, 1977, 3, p. 95

Note 5. The Bank of Korea, "Current Status of Technology Imports of Korean Firms, "Weekly Report of Domestic and Foreign Economies, Seoul, 1984, 9.29, p. 16.

Note 6. Sung Chul Kim, "Policy Directions to Support Science and Technology Progress," Technology Management, Korea Industrial Research Institutes, 1985. 2, p.6-9

Note 7. Ministry of Science and Technology, Science and Technology Annual, Korea, 2011

Note 8. United Nations Conference on Trade and Development, Guidelines for Study of the Transfer of Technology to Developing Countries, New York, 2010, p.36 37

Note 9. Behrman, Jack N. and Wallender, Harvey W., Transfers of Manufacturing Technology Within Multinational Enterprises, Cambridge,Mass, : Ballinger Publishing Co., 2011, p.4 6.

Note 10. Business Korea: Monthly Economic \& Financial Review, Business Korea, Seoul, July 2010,

Note 11. From the viewpoint of policy execution, it is asserted that "the best action that an LDC government could take is providing information on techniques" Ross W. Hammond, "Technology Transfer System for Small Industries," in OECD, Transfer of Technology for Small Industries, 2009, p. 190-200.

Note 12. An empirical study on LDC's by Lawrence J. White argues that greater labor intensity in LDC manufacturing is feasible and would be efficient only if a well-directed R \& D is performed and that the possibilities are unlimited. Lawrence J. White, "The Evidence on Appropriate Factor Proportions for Manufacturing in Less Developed Countries: A Survey, "Economic Development and Culture Change, Oct. 2009, p. 27-59.

Note 13. L.H. White, "Appropriate Technology, X-Inefficiency, and a Competitive Environment: Some Evidence from Pakistan," Public Policy XC, Nov. 2007, p. 575-589.

Note 14. G. Ranis, "Technology, Employment and Growth; the Japanese Experience," in ILO, Automation in Developing Countries, Geneva, 2009.

Note 15. World Bank, World Development. 2007, p. 5.

Note 16. P.C. Timmer, "Choice of Technique in Indonesia," and L.T. Wells, "Economic Man and Engineering Man; Choice of Technology in a Low Wages Countries," both in D, Morawetz el.al., Studies of Inappropriate Technologies for Development, Harvard University, Center for International Affairs, Monograph, 2005.

Note 17. Successful cases of technological adaptation are investigated in W,P, Strassman, Technologica Choice and Economic Development: The Manufacturing Experience of Mexico and Puerto Rico, Ithaca, CornelI University Press, 2005.

Note 18. Hans W. Singer pointed out that developing countries actually do not know what technologies the developed countries have, which of those are suitable and lucrative to them and how to adopt those advanced technologies. Gerald M. Meier, Leading Issues in Economic Development, Oxford University Press, New York, 2009, p. 399. 
Table 1. Annual status for technology export \& import

(Unit: million US\$)

\begin{tabular}{|l|l|l|l|l|l|}
\hline & $\begin{array}{l}\text { Size } \\
\text { Technology } \\
\text { Trade } \\
(\mathrm{A}+\mathrm{B})\end{array}$ & $\begin{array}{l}\text { Export Amount } \\
(\mathrm{A})\end{array}$ & $\begin{array}{l}\text { Technology } \\
\text { Import Amount } \\
(\mathrm{B})\end{array}$ & $\begin{array}{l}\text { Technology } \\
\text { Trade Balance } \\
(\mathrm{A}-\mathrm{B})\end{array}$ & Remark \\
\hline 2001 & 3,262 & 619 & 2,643 & $-2,024$ & \\
\hline 2002 & 3,360 & 638 & 2,721 & $-2,083$ & \\
\hline 2003 & 4,053 & 816 & 3,236 & $-2,420$ & \\
\hline 2004 & 5,564 & 1,416 & 4,147 & $-2,731$ & \\
\hline 2005 & 6,150 & 1,625 & 4,525 & $-2,900$ & \\
\hline 2006 & 6,734 & 1,897 & 4,838 & $-2,941$ & \\
\hline 2007 & 7,282 & 2,178 & 5,103 & $-2,925$ & \\
\hline 2008 & 8,200 & 2,530 & 5,670 & $-3,140$ & \\
\hline 2009 & 12,020 & 3,582 & 8,438 & $-4,856$ & \\
\hline 2010 & 13,579 & 3,345 & 10,234 & $-6,889$ & \\
\hline
\end{tabular}

Source: National Science \& Technology Commission (April 11, 2012)

Table 2. The degree of the absorption and application of imported technologies

$(\%)$

\begin{tabular}{|l|l|l|l|}
\hline \multicolumn{1}{|c|}{ Industry } & Partial Absorption & Perfect Absorption & $\begin{array}{c}\text { Modification or } \\
\text { Application }\end{array}$ \\
\hline Total & 27.7 & 35.2 & 40.9 \\
\hline Mining & 25.0 & 25.0 & 50.0 \\
\hline Food & 25.8 & 45.1 & 29.0 \\
\hline Fiber \& Texture & 46.6 & 16.6 & 36.6 \\
\hline Timber,Paper\&Pulp & 36.2 & 27.2 & 36.3 \\
\hline Petro-Chemical & 14.2 & 48.2 & 37.4 \\
\hline Non-metal Ore & 19.9 & 53.3 & 26.6 \\
\hline Basic Metal & 15.7 & 52.6 & 31.5 \\
\hline General Machinery & 29.4 & 17.6 & 52.8 \\
\hline Transaction Machines & 13.3 & 26.6 & 60.1 \\
\hline $\begin{array}{l}\text { Electricity \& } \\
\text { Electronics }\end{array}$ & 20.0 & 16.0 & 64.0 \\
\hline
\end{tabular}

Source: A Survey of 289 large firms conducted by the Federation of Korean Industries in 2011

Table 3. Levels of technology by the size of importing firms

$(\%)$

\begin{tabular}{|l|l|l|l|l|}
\hline & Fluid Pattern & $\begin{array}{l}\text { Transactional } \\
\text { Pattern }\end{array}$ & Specific Pattern & Total \\
\hline Large Firms & $13(15.9)$ & $52(63.4)$ & $17(20.7)$ & $82(100)$ \\
\hline $\begin{array}{l}\text { Small \& Medium } \\
\text { Firms }\end{array}$ & $7(15.6)$ & $28(62.2)$ & $10(22.2)$ & $45(100)$ \\
\hline Total & $20(15.7)$ & $80(63.0)$ & $27(21.3)$ & $127(100)$ \\
\hline
\end{tabular}

Source: A Survey of 289 large firms conducted by the Federation of Korean Industries in 2011 
Table 4. Status of technology export on each industry

(Unit: million USD)

\begin{tabular}{|c|c|c|c|c|c|c|c|}
\hline & \multicolumn{2}{|r|}{2008} & \multicolumn{2}{|r|}{2009} & \multicolumn{2}{|r|}{2010} & \multirow[b]{2}{*}{ Remark } \\
\hline & Amount & $\begin{array}{l}\text { Variation against } \\
\text { last year }\end{array}$ & Amount & $\begin{array}{c}\text { Variation against } \\
\text { last year }\end{array}$ & Amount & $\begin{array}{c}\text { Variation against } \\
\text { last year }\end{array}$ & \\
\hline Electricity \& Electronic & $1,643.5$ & 16.7 & $2,452.5$ & 49.2 & $1,663.1$ & -32.5 & \\
\hline Machinery & 570.7 & 24.3 & 717.7 & 25.8 & 747.7 & 4.2 & \\
\hline Telecommunication & 167.3 & 27.0 & 172.2 & 2.9 & 153.2 & -11.0 & \\
\hline Chemistry & 34.7 & -27.2 & 30.0 & -13.5 & 6.7 & -77.6 & \\
\hline Crude Materials & 8.7 & 54.9 & 35.2 & 305.6 & 2.3 & -93.6 & \\
\hline Textile & 0.4 & 1.2 & 40.4 & $9,525.1$ & 19.6 & -51.5 & \\
\hline $\begin{array}{l}\text { Agriculture, Forest, } \\
\text { Fishery }\end{array}$ & 5.0 & 47.7 & 4.2 & -15.5 & 11.6 & 172.5 & \\
\hline Construction & 26.4 & -25.5 & 89.2 & 238.5 & 30.6 & -65.7 & \\
\hline Others & 73.0 & -15.7 & 40.5 & -44.5 & 710.1 & $2,307.8$ & \\
\hline Total & $2,529.6$ & 16.1 & $3,581.9$ & 41.6 & $3,344.9$ & -6.6 & \\
\hline
\end{tabular}

Source: Ministry of Strategy \& Finance, Korea 2012

Table 5. Technology trade status on major partner countries in 2010

(Unit: million USD, \%)

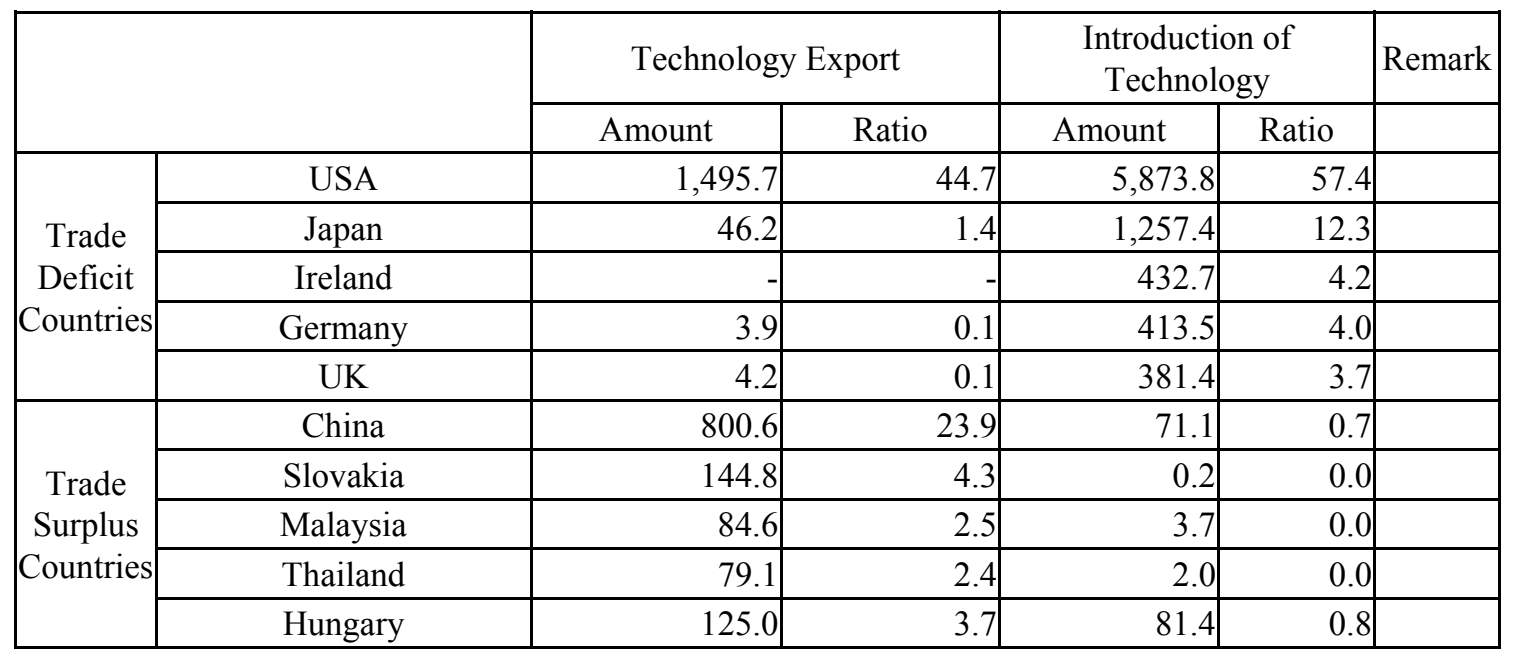

Source: Ministry of Strategy \& Finance, Korea 2012

Table 6. The size of importing firms and selection of import methods

\begin{tabular}{|l|l|l|l|l|}
\hline Selection of Import Method & Importing Firms & $\begin{array}{l}\text { Exporting } \\
\text { Firms }\end{array}$ & $\begin{array}{l}\text { Mutual } \\
\text { Agreement }\end{array}$ & Total \\
\hline The Size of Importing Firms & & $4(4.9)$ & $9(11.1)$ & $81(100)$ \\
\hline Large Firms & $68(84.0)$ & $2(4.4)$ & $12(26.7)$ & $45(100)$ \\
\hline Small \& Medium Firms & $31(68.9)$ & &
\end{tabular}

Source: Ministry of Education, Science and Technology 2010 
Table 7. Types of R \& D in Korean firms

(Unit: number of firms. \%)

\begin{tabular}{|l|l|l|l|l|}
\hline Size \& Types & Self-development & $\begin{array}{l}\text { Joint Development } \\
\text { with Foreign }\end{array}$ & $\begin{array}{l}\text { Joint with } \\
\text { Domestic } \\
\text { Research Institutes }\end{array}$ & Total \\
\hline Large Firms & $36(85.7)$ & $4(9.5)$ & $2(4.8)$ & $42(100.0)$ \\
\hline $\begin{array}{l}\text { Small \& Medium } \\
\text { Firms }\end{array}$ & $20(76.9)$ & $6(23.1)$ & $0(0.0)$ & $26(100.0)$ \\
\hline Total & $56(82.3)$ & 10 & 2 & $68(100.0)$ \\
\hline
\end{tabular}

Source: Ministry of Science \& Technology, 2011 